\title{
Tentative Assignments of Fundamental Vibrations of Thio- and Selenoamides. IV. Addition Compounds of Tetramethylthiourea with Iodine, Methyl Iodide and Metal Halides
}

\author{
G. BORCH, ${ }^{a}$ P. KLÆBOE, ${ }^{b}$ P. H. NIELSEN ${ }^{c}$ and L. M. PEDERSEN ${ }^{c}$
}

${ }^{a}$ Chemistry Department A, The Technical University of Denmark, DK-2800 Lyngby, Denmark, ${ }^{b}$ Department of Chemistry, University of Oslo, Oslo 3, Norway and ${ }^{\mathrm{c}}$ Chemical Laboratory II, The H. C. Ørsted Institute, DK-2100 Copenhagen, Denmark

The perturbations of the vibrational modes of tetramethylthiourea (TMTU) in addition compounds (complexes) with iodine, methyl iodide, and methyl halides $\left(\mathrm{ZnCl}_{2}, \mathrm{CdCl}_{2}, \mathrm{CdI}_{2}, \mathrm{HgCl}_{2}\right.$, and $\mathrm{HgI}_{2}$ ) have been studied. The changes of force constants obtained from normal coordinate analyses agreed well with the charge redistributions calculated in the CNDO-MO approximation using model compounds. A limited CNDO/S-CI procedure was used to assign the main UV transitions for TMTU and its addition compounds with iodine, methyl iodide, and strong acids. The CNDO occupied orbital eigenvalues and assignments for the photoelectron spectrum of TMTU in the 7-13 $\mathrm{eV}$ range are in agreement with experimental results. The study demonstrates that the semiempirical $\mathrm{CNDO} / \mathrm{S}$ method may serve to explain infrared, ultraviolet, and photoelectron spectra of TMTU and some of its addition compounds. Some limitations for the interpretation of the infrared spectra are discussed.

We have previously shown ${ }^{1}$ that certain IR absorption bands of thioureas (termed A-G bands) behave in a characteristic way when the thioureas are deuterated, $S$-alkylated, transformed into metal complexes, or when sulfur is replaced with selenium. Recently, the vibrational spectra of tetramethylthiourea (TMTU) including a normal coordinate treatment of TMTU and five isotopic species ${ }^{2}$ and of tetramethylselenourea and two deuterated species $^{3}$ were published. In the present paper we report the changes in the IR spectra of TMTU when forming addition compounds with iodine
(TMTU $\cdot \mathrm{I}_{2}$ ), methyl iodide (TMTU $\cdot \mathrm{CH}_{3} \mathrm{I}$ or $S$ methylisothiouronium iodide), and metal halides (2:1 complexes with $\mathrm{HgI}_{2}, \mathrm{CdCl}_{2}, \mathrm{CdI}_{2}$ and $\mathrm{ZnCl}_{2}$, and 1:1 complex with $\mathrm{HgCl}_{2}$ ). In a forthcoming paper the vibrational spectra of the addition compound between tetramethylselenourea and iodine will be discussed in connection with a normal coordinate analysis (NCA).

Recently, the charge transfer complex formed between tetramethylurea and iodine was studied in nonpolar solvents by IR spectroscopy. ${ }^{4}$ From an NCA it was concluded that mainly the $\mathrm{CO}$ and $\mathrm{CN}$ stretching and the $\left(\mathrm{CH}_{3}\right)_{2} \mathrm{~N}$ deformation vibrations are perturbed by complex formation. Qualitatively, this was explained by electronic redistribution caused by charge transfer from tetramethylurea to iodine., ${ }^{4,5}$

TMTU forms a very strong $1: 1$ complex with iodine $^{6,7}$ and the IR spectrum of a solution has been reported. ${ }^{8-10}$ Since the IR results are partly conflicting we have reinvestigated the spectrum of TMTU $\cdot I_{2}$ in solution and as a film on a $\mathrm{KBr}$-disc. The Raman bands below $300 \mathrm{~cm}^{-1}$ may be correlated with the strength of the donor-acceptor interaction ${ }^{11}$ and this region was therefore recorded for TMTU $\cdot I_{2}$ in chloroform solution.

The IR spectrum of TMTU $\cdot \mathrm{CH}_{3} \mathrm{I}$ has only been incompletely reported ${ }^{1}$ and was recorded in the $200-4000 \mathrm{~cm}^{-1}$ range. Though the IR and Raman spectra of metal halide complexes of TMTU have been discussed in several papers, ${ }^{12-18}$ complete listings of the observed frequencies in the region $200-2000 \mathrm{~cm}^{-1}$ have not appeared. Therefore, we 
determined the IR spectra of five selected metal halide complexes. Since the frequency shifts of the TMTU bands on complex formation with the metal halides were quite similar, we used the mean values of these shifts as characteristic for a typical complex.

Generalised valence force fields (GVFF) of these complexes are correlated with $\mathrm{CNDO} / \mathrm{S}$ electronic densities for feasible model compounds. The usefulness of the CNDO/S method is further demonstrated by correlation with ultraviolet and photoelectron data.

\section{EXPERIMENTAL}

The IR spectra were recorded on Perkin-Elmer models 180, 225, 283 and/or 337 spectrometers. Spectra of TMTU solutions without and with addition of iodine were recorded on the same paper and are believed to be correct within $1-2 \mathrm{~cm}^{-1}$ for well-resolved bands. All shifts were determined in ca. $1 \mathrm{M}$ solutions in $\mathrm{CS}_{2}$ and $\mathrm{CHCl}_{3}$. In $\mathrm{CS}_{2}$, even with a double excess of iodine, only a $50 \%$ conversion of TMTU to the iodine complex took place. This complies with thermodynamic evidence ${ }^{6}$ that polar solvents like $\mathrm{CHCl}_{3}$ stabilize strong chargetransfer complexes such as TMTU $\cdot I_{2}$ more than do nonpolar solvents $\left(\mathrm{CS}_{2}\right)$. The measurements in $\mathrm{CHCl}_{3}$ solution were carried out in solutions with

Table 1. Observed and calculated shifts $\left(\mathrm{cm}^{-1}\right)$ of the infrared bands of tetramethylthiourea on addition of methyl iodide, iodine, and metal halides.

\begin{tabular}{|c|c|c|c|c|c|c|c|c|c|}
\hline & & & Tetramethylthiourea & Shifts & $s^{a}$ on a & additic & on of & & \\
\hline Spe & $\operatorname{cies}^{b}$ & Position $^{b}$ & Description $(\mathrm{PED}, \%)^{c}$ & $\mathrm{CH}_{3} \mathrm{I}$ & & $\mathrm{I}_{2}{ }^{e}$ & & Meta & al halide ${ }^{\prime}$ \\
\hline & & & & Obs & Calc & Obs & Calc & Obs & Calc \\
\hline a & $v_{7}$ & 1499 & $\begin{array}{l}v_{\mathrm{as}} \mathrm{N}_{2} \mathrm{CS}(30), \delta \mathrm{NCN}(15), \rho \mathrm{Me}_{2} \mathrm{~N}(25), \\
v_{\mathrm{as}} \mathrm{Me}_{2} \mathrm{~N}(16)\end{array}$ & +94 & +98 & +47 & +48 & +51 & +52 \\
\hline & $v_{12}$ & 1360 & $\nu \mathrm{CH}_{3}^{\text {cis }} \mathrm{N}(11), \delta \mathrm{CH}_{3}^{\mathrm{cis}}(98)$ & +29 & +32 & +19 & +20 & +17 & +12 \\
\hline & $v_{14}$ & 1275 & $v_{\mathrm{s}} \mathrm{NCN}(25), \delta \mathrm{CH}_{3}^{\mathrm{tr}} \mathrm{NC}(20), v \mathrm{CH}_{3}^{\mathrm{cis}} \mathrm{N}(35)$ & -12 & -10 & -9 & -9 & +7 & +12 \\
\hline & $v_{15}$ & 1137 & $v_{\mathrm{as}} \mathrm{N}_{2} \mathrm{CS}(27), v_{\mathrm{as}} \mathrm{Me}_{2} \mathrm{~N}(36), \rho \mathrm{CH}_{3}(30)$ & +6 & +2 & 0 & -4 & 0 & 0 \\
\hline & $v_{16}$ & 1113 & $\rho \mathrm{CH}_{3}(83), \delta \mathrm{CH}_{3}(12)$ & -7 & -7 & -7 & -3 & -12 & -4 \\
\hline & $v_{17}$ & 1061 & $\rho \mathrm{CH}_{3}(89)$ & -10 & -5 & 0 & 0 & 0 & -3 \\
\hline & $v_{19}$ & 960 & $v_{\mathrm{s}} \mathrm{N}_{2} \mathrm{CS}(10), v_{\mathrm{s}} \mathrm{Me}_{2} \mathrm{~N}(56), \rho \mathrm{CH}_{3}(30)$ & +6 & +1 & -10 & -9 & -12 & -10 \\
\hline & $v_{20}$ & 631 & $v_{\mathrm{s}} \mathrm{N}_{2} \mathrm{CS}(43), v_{\mathrm{s}} \mathrm{Me}_{2} \mathrm{~N}(16), \delta \mathrm{Me}_{2} \mathrm{~N}(29)$ & -20 & -15 & -12 & -14 & 0 & +1 \\
\hline & $v_{21}$ & 492 & $v \mathrm{CS}(51), \delta \mathrm{CH}_{3}^{\mathrm{tr}} \mathrm{NC}(22)$ & -41 & -39 & -24 & -22 & -14 & -18 \\
\hline & $v_{22}$ & 396 & $\delta \mathrm{CH}_{3}^{\text {cis }} \mathrm{NC}(29), \delta \mathrm{Me}_{2} \mathrm{~N}(33), v_{\mathrm{s}} \mathrm{NCN}(15)$ & -4 & -4 & 0 & -1 & -13 & -10 \\
\hline & $v_{23}$ & 303 & $\tau \mathrm{CN}(43), \delta \mathrm{NCN}(24), \delta \mathrm{CH}_{3}^{\mathrm{tr}} \mathrm{NC}(16)$ & +19 & +9 & $0^{\mathrm{g}}$ & 0 & +3 & +2 \\
\hline b & $v_{38}$ & 1369 & $v_{\mathrm{as}} \mathrm{NCN}(10), \delta \mathrm{NCS}(6), \rho \mathrm{Me}_{2} \mathrm{~N}(27), v_{\mathrm{as}} \mathrm{Me}_{2} \mathrm{~N}(29)$ & +30 & +25 & +16 & +14 & +21 & +20 \\
\hline & $v_{39}$ & 1360 & $\nu \mathrm{C} \mathrm{H}_{3}^{\mathrm{cis}} \mathrm{N}(12), \delta \mathrm{CH}_{3}^{\mathrm{cis}}(98)$ & +21 & +24 & +19 & +18 & +17 & +11 \\
\hline & $v_{40}$ & 1334 & $\delta_{\mathrm{s}} \mathrm{CH}_{3}(93), v \mathrm{CH}_{3}^{\mathrm{tr}} \mathrm{N}(16)$ & -5 & -5 & 0 & -2 & 0 & +6 \\
\hline & $v_{41}$ & 1214 & $v_{\text {as }} \mathrm{NCN}(18), \nu \mathrm{CH}_{3}^{\mathrm{tr}} \mathrm{N}(26), \rho \mathrm{CH}_{3}(45)$ & -10 & -7 & -4 & -6 & 0 & -5 \\
\hline & $v_{42}$ & 1137 & $\rho \mathrm{CH}_{3}(64), \tau \mathrm{CN}(8), v_{\mathrm{as}} \mathrm{NCN}(4)$ & +6 & -2 & 0 & -1 & 0 & 0 \\
\hline & $v_{43}$ & 1094 & $v_{\mathrm{as}} \mathrm{NCN}(25), \rho \mathrm{CH}_{3}(47)$ & +10 & +14 & 0 & +4 & +3 & +8 \\
\hline & $v_{44}^{40}$ & 1061 & $\rho \mathrm{CH}_{3}(87)$ & -10 & -5 & 0 & -1 & 0 & -3 \\
\hline & $v_{46}^{44}$ & 930 & $v \mathrm{CH}_{3}^{\mathrm{cis}} \mathrm{N}(48), v \mathrm{CH}_{3}^{\mathrm{tr}} \mathrm{N}(21)$ & +3 & +9 & 0 & +3 & 0 & +2 \\
\hline & $v_{47}$ & 886 & $\tau \mathrm{CN}(47), v \mathrm{CH}_{3}^{\mathrm{tr}} \mathrm{N}(17)$ & -13 & -10 & -12 & -12 & 0 & +2 \\
\hline & $v_{49}$ & 442 & $v_{\text {as }} \mathrm{NCN}(7), \delta \mathrm{CH}_{3}^{\text {tr }} \mathrm{NC}(46)$ & -26 & -23 & -8 & -6 & 0 & 0 \\
\hline
\end{tabular}

a 24 fundamentals of TMTU (Ref. 2) display shifts of $2 \mathrm{~cm}^{-1}$ or less in the IR spectra $\left(200-4000 \mathrm{~cm}^{-1}\right) \mathrm{and}^{-1}$ are not included. The corresponding calculated shifts do not exceed $3 \mathrm{~cm}^{-1}$. The region below $200 \mathrm{~cm}^{-1}$ has not been investigated. ${ }^{b}$ As used in the calculations of Ref. 2. ${ }^{c}$ Based upon the L-matrix and PED of parent TMTU. The abbreviations are $v=$ stretch, $\delta=$ deformation, $\rho=$ rock, $\tau=$ torsion. The subscripts as $=$ antisymmetric and $\mathrm{s}=$ symmetric refer to the local symmetry of the groups in question. The designations cis and tr refer to the methyl groups cis and trans relative to sulfur. ${ }^{d}$ Spectra run in $\mathrm{KBr}$-discs (in the region $200-400 \mathrm{~cm}^{-1}$ in CsI-discs). ${ }^{e}$ Values from solution spectra $\left(\mathrm{CHCl}_{3}\right){ }^{f} \mathrm{Mean}$ values of the spectra of TMTU $\mathrm{ZnCl}_{2}, \mathrm{TMTU}_{2} \mathrm{CdI}_{2}, \mathrm{TMTU}_{2} \mathrm{CdCl}_{2}$, TMTU ${ }_{2} \mathrm{HgI}_{2}$, and $\mathrm{TMTUHgCl}$, run in $\mathrm{CsI}$ and $\mathrm{KBr}$-discs. ${ }^{g}$ Raman value $\left(\mathrm{CHCl}_{3}\right.$ solution). 
TMTU to iodine mol ratios varying from $1: \frac{1}{2}$ to $1: 3$. The best spectra were obtained with a $50 \%$ excess of iodine. Spectra of this solution were recorded with different cell-thicknesses and the mean values for the iodine shifts are given in Table 1. The shifts determined when the spectrum of TMTU $\cdot I_{2}$ was run as a film on a $\mathrm{KBr}$-disc were somewhat larger (listed in the same order as in Table 1): $+59,+22,-14,+3,-10,0,-17,-19$, $-22,0,0 \mathrm{~cm}^{-1}$ in species $a$ and $+27,+22,0,-6$, $+3,0,0,0,-12,-15 \mathrm{~cm}^{-1}$ in species $b$. The IR spectra of TMTU $\cdot \mathrm{CH}_{3} \mathrm{I}$ and of the metal halide complexes were recorded in the range 200-4000 $\mathrm{cm}^{-1}$ in $\mathrm{KBr}$ and CsI discs with different concentrations. The mean values for the shifts are listed in Table 1.

The Raman spectra of TMTU $\cdot \mathrm{I}_{2}$ in $\mathrm{CHCl}_{3}$ solution were recorded with a Cary 81 spectrometer equipped with a $\mathrm{He}-\mathrm{Ne}$ laser $(6328 \AA)$ in the axial illumination mode. The following lines were observed in the region below $200 \mathrm{~cm}^{-1}\left(\mathrm{CHCl}_{3}\right)$ :
$114 \mathrm{~m}\left(\mathrm{I}_{3}{ }^{-}\right), 138 \mathrm{~s}$ (probably ${ }^{11} \mathrm{I}-\mathrm{I}$ stretch), $182 \mathrm{w}$, $193 \mathrm{w}, \mathrm{sh}$. The ultraviolet spectra were recorded on a Cary 11 spectrophotometer at room temperature in a concentration range of TMTU and the acceptor generally between $10^{-2}$ and $10^{-4} \mathrm{M}$. The results are given in Table 3. Noise-decoupled ${ }^{13} \mathrm{C}$ NMR spectra were determined with a Bruker WH 90 system $(22.63 \mathrm{MHz})$ operating in the Fourier transform mode. The spectra of TMTU and TMTU. $I_{2}$ were examined as $1 \mathrm{M}$ solutions in $\mathrm{CDCl}_{3}$ and shieldings were measured relative to internal TMS. $\mathrm{He}$ (I) photoelectron spectra were obtained on a Perkin-Elmer PS 18 spectrometer calibrated by measuring the ${ }^{2} P_{3 / 2}$ peaks of $\mathrm{Ar}$ and Xe present with the samples.

\section{CALCULATIONS}

Since the molecular structure of TMTU $I_{2}$ has not been determined, the geometry of TMTU was

Table 2. A general valence force field (GVFF) of tetramethylthiourea (TMTU) ${ }^{a}$ and the changes calculated for the addition products with methyl iodide, iodine, and metal halides $\left(\mathrm{MeX}_{2}\right)$.

\begin{tabular}{|c|c|c|c|c|c|}
\hline \multirow{2}{*}{ Symbol $^{a}$} & \multirow{2}{*}{ Description $^{b}$} & \multirow{2}{*}{$\begin{array}{l}\text { GVFF of } \\
\text { TMTU }^{c}\end{array}$} & \multicolumn{3}{|c|}{ Changes relative to TMTU } \\
\hline & & & $\mathrm{TMTU} \cdot \mathrm{CH}_{3} \mathrm{I}$ & $\mathrm{TMTU} \cdot \mathrm{I}_{2}$ & $\mathrm{TMTU} \cdot \mathrm{MeX}_{2}$ \\
\hline $\begin{array}{l}\text { Stretching } \\
\mathbf{K}_{\mathbf{D}} \\
\mathbf{K}_{\mathrm{R}} \\
\mathrm{F}_{\mathrm{R}_{\mathrm{R}}} \\
\mathrm{K}_{\mathrm{P}_{1}} \\
\mathrm{~K}_{\mathrm{P}_{2}}\end{array}$ & $\begin{array}{l}\nu \mathrm{CS} \\
v \mathrm{CN} \\
\nu \mathrm{CN} / \nu \mathrm{CN} \\
v \mathrm{CH}_{3}^{\text {cis }}-\mathrm{N} \\
v \mathrm{CH}_{3}^{\text {trans }}-\mathrm{N}\end{array}$ & $\begin{array}{l}4.029 \\
4.799 \\
1.613 \\
5.414 \\
5.393\end{array}$ & $\begin{array}{l}-0.76 \\
+0.17 \\
-0.16 \\
+0.20 \\
+0.23\end{array}$ & $\begin{array}{l}-0.48 \\
-0.08 \\
-0.05 \\
+0.14 \\
-0.08\end{array}$ & $\begin{array}{l}-0.51 \\
+0.08 \\
-0.07 \\
+0.16 \\
-0.10\end{array}$ \\
\hline $\begin{array}{l}\text { The } \mathrm{N}-\mathrm{C} \\
\mathrm{H}_{\delta_{1}} \\
\mathrm{H}_{\delta_{2}} \\
\mathrm{~F}_{\mathrm{R} \delta_{2}} \\
\mathrm{~F}_{\mathrm{R} \delta_{3}}\end{array}$ & $\begin{array}{l}\mathrm{N} \text { grouping } \\
\delta \mathrm{NCN} \\
\delta \mathrm{NCS} \\
\nu \mathrm{CN} / \delta \mathrm{NCS} \\
\nu \mathrm{CN} / \delta \mathrm{NCS}\end{array}$ & $\begin{array}{l}1.123 \\
0.800 \\
0.981 \\
0.408\end{array}$ & $\begin{array}{l}+0.91 \\
+0.04 \\
+0.54 \\
+0.48\end{array}$ & $\begin{array}{l}+0.21 \\
+0.06 \\
+0.38 \\
+0.33\end{array}$ & $\begin{array}{l}+0.13 \\
0 \\
+0.61 \\
+0.55\end{array}$ \\
\hline $\begin{array}{l}\text { The }\left(\mathrm{CH}_{3}\right)_{2} \\
\mathbf{H}_{\gamma_{1}} \\
\mathbf{H}_{\gamma_{2}} \\
\mathbf{H}_{\gamma_{3}}\end{array}$ & $\begin{array}{l}\text { grouping } \\
\delta \mathrm{CH}_{3}^{\text {cis }} \mathrm{NC} \\
\delta \mathrm{CH}_{3}^{\text {trans }} \mathrm{NC} \\
\delta \mathrm{CH}_{3} \mathrm{NCH}_{3}\end{array}$ & $\begin{array}{l}1.657 \\
1.916 \\
1.065\end{array}$ & $\begin{array}{l}-0.37 \\
-0.42 \\
+0.25\end{array}$ & $\begin{array}{l}-0.01 \\
-0.12 \\
+0.05\end{array}$ & $\begin{array}{l}-0.42 \\
+0.29 \\
+0.19\end{array}$ \\
\hline $\begin{array}{l}\text { Others } \\
\mathrm{H}_{\beta} \\
\mathrm{F}_{\beta} \\
\mathrm{F}_{\mathrm{P}_{2 \beta}} \\
\mathrm{H}_{\tau_{3}}\end{array}$ & $\begin{array}{l}\delta \mathrm{HCN} \\
\delta \mathrm{HCN} / \delta \mathrm{HCN} \\
\nu \mathrm{CH}_{3}^{\text {trans }}-\mathrm{N} / \delta \mathrm{HCN} \\
\tau \mathrm{CN}\end{array}$ & $\begin{array}{r}0.711 \\
-0.059 \\
0.373 \\
1.013\end{array}$ & $\begin{array}{l}+0.01 \\
+0.019 \\
+0.16 \\
+0.01\end{array}$ & $\begin{array}{l}+0.01 \\
+0.010 \\
+0.06 \\
-0.05\end{array}$ & $\begin{array}{l}0 \\
+0.007 \\
+0.03 \\
+0.01\end{array}$ \\
\hline
\end{tabular}

${ }^{a}$ The GVFF of Ref. 2 was transferred directly except for the force constants listed in the table and for $\mathbf{K}_{\mathrm{r}}, \mathbf{H}_{\alpha}, \mathbf{H}_{\Delta}$, $\mathbf{H}_{\tau}$ and $\mathbf{H}_{\tau}$, where calculations produced no change. ${ }^{b}$ For abbreviations $c f$. footnote $c$, Table 1 . ${ }^{c}$ In units of $\mathrm{mdyn} / \AA$ (stretch constants), mdyn/rad (stretch-bend interaction constants), and $\mathrm{mdyn} \AA /(\mathrm{rad})^{2}$ (bending and torsion constants). 
used in all calculations. A recent determination of the crystal structure of the related $N$-methylthiocaprolactam-iodine 1:1 complex ${ }^{19}$ showed that bond lengths and bond angles are not significantly altered on iodine complex formation. The iodine molecule coordinates to sulfur with a $\mathrm{C}-\mathrm{S}-\mathrm{I}$ angle of $105-110^{\circ}$ with the iodine molecule nearly co-planar with the $\mathrm{N}-\mathrm{CS}-\mathrm{C}$ group. ${ }^{19,20}$ From the 1:1 thiourea-iodine adduct, however, a $2: 1$ compound is eventually formed and the crystal structure shown to be ionic. ${ }^{20}$ The $C_{2}$-symmetry of TMTU apparently breaks down on complex formation with iodine, and strictly we should distinguish between the $\left(\mathrm{CH}_{3}\right)_{2} \mathrm{~N}$-groups cis and trans to to iodine. In the metal halide complexes the CS distance increases, ${ }^{21,22}$ but the remaining distances and interbond angles are not significantly altered. When thiourea is converted to $S$-methylthiouronium salts the geometry is hardly changed ${ }^{23,24}$ and we have used the geometry of TMTU both in the case of TMTU $\cdot \mathrm{CH}_{3} \mathrm{I}$ and in the TMTU $\cdot$ metal halide adducts.

The NCA of TMTU was started with a leastsquares fit identical to that described previously ${ }^{2}$ except that all the observed frequencies of the isotopically labelled compounds were removed and only the fundamentals of the parent molecule were included. This was done since the IR shifts of isotopically labelled addition compounds have not been determined. Since the NCA led to physically unrealistic values for the force constants the following constraints were introduced to reduce the number of independent constants to a tractable number: (1) The diagonal force constants should be included in order to secure that all internal coordinates were taken into account, and (2) only those interaction constants which were necessary to reproduce the shifts observed in the addition compounds were allowed to vary. All other force constants were given the previous values. ${ }^{2}$

Among the 54 vibrational modes for TMTU, ${ }^{2}$ 21 are shifted $2 \mathrm{~cm}^{-1}$ or more upon complex formation as observed in the IR spectra of TMTU $\cdot I_{2}, \quad T M T U \cdot \mathrm{CH}_{3} \mathrm{I}$ and TMTU $\cdot$ metal halide. These vibrational fundamentals are included in Table 1, while the remaining 33 modes which were perturbed less than $2 \mathrm{~cm}^{-1}$ are not included. Simultaneous NCA were now performed on the spectra of TMTU and the three complexes. With the inclusion of the five interaction constants $F_{\mathrm{R}}$, $F_{\mathrm{R} \delta_{2}}, F_{\mathrm{R} \delta_{3}}, F_{\beta}$ and $F_{\mathrm{P}_{2} \beta}$ listed in Table 2 (the number of off-diagonal elements were kept as low as possible) converging solutions were obtained with good agreement between experimental and calculated shifts (Table 1). However, the force constants given in Table 2 should be taken with due reservation. In addition to the errors caused by the approximated geometry, exploratory calculations indicate that the choice of other interaction constants leads to alternative solutions which have only the gross features (discussed below) in common with the force field of Table 2 .

Semi-empirical all valence-electron molecular orbital calculations were carried out using both the $\mathrm{CNDO} / 2$ and the $\mathrm{CNDO} / \mathrm{S}^{25}$ parametrisations, but since the electronic densities were almost identical, only the $\mathrm{CNDO} / \mathrm{S}$ densities are reproduced (Fig. 1). A modified CNDO/S-CI program ${ }^{26}$ was provided by Professor G. Pfister-Guillouzo and extended to molecules containing 40 atoms $/ 100$ orbitals. Excited states were calculated from the ground state occupied and virtual orbitals by a CI procedure limited to the 20 lowest-energy, singleexcited configurations. Calculations were made on TMTU and the TMTU $\cdot \mathrm{CH}_{3}{ }^{+}$ion. TMTU $S$-oxide served as a model substance for the TMTU $\cdot I_{2}$ complex using an $\mathrm{S}-\mathrm{O}$ distance of $1.50 \AA$ and a $\mathrm{C}-\mathrm{S}-\mathrm{O}$ angle of $106^{\circ}$. For the TMTU $\cdot$ metal halide complexes we used a hypothetical 1:1 TMTU $\cdot \mathrm{MgCl}_{2}$ complex with $\mathrm{Mg}-\mathrm{S}$ and $\mathrm{Mg}-\mathrm{Cl}$ distances of 2.60 and $2.53 \AA$, respectively, and $\mathrm{C}-\mathrm{S}-\mathrm{Mg}$ and $\mathrm{Cl}-\mathrm{Mg}-\mathrm{Cl}$ angles of $110^{\circ}$. The calculated energies and transitions are compared with our experimental results in Tables 3 and 4.

\section{RESULTS AND DISCUSSION}

In Table 1 are summarised the observed and calculated shifts with a description of the fundamentals in terms of the contributing skeletal modes. Gosavi et al. ${ }^{10}$ claim the significant change in the spectrum of TMTU on complex formation with iodine to be a shift to lower frequency and increased intensity of a band near $990 \mathrm{~cm}^{-1}$. However, this band does not occur in our spectra of $\mathrm{TMTU}^{2}$ and is presumably due to a solvent $\left(\mathrm{CCl}_{4}\right)$ band.

In one instance (the overlapping fundamentals $v_{15}$ and $v_{42}$ near $1137 \mathrm{~cm}^{-1}$ ) the shifts in Table 1 cannot be regarded as conclusive. On iodine addition to TMTU the band becomes much weaker and at the same time a band near $1150 \mathrm{~cm}^{-1}$ (in TMTU assigned ${ }^{2}$ a combination mode) gains intensity and finally becomes much stronger than the band near 
Table 3. Ultraviolet absorption of tetramethylthiourea (TMTU) and its compounds with methyl iodide, iodine and sulfuric acid assigned from CNDO/S-CI calculations.

\begin{tabular}{|c|c|c|c|c|c|c|c|c|c|}
\hline \multirow{3}{*}{ Compound } & \multirow{3}{*}{ Solvent } & \multicolumn{8}{|c|}{ Transitions $^{a}$} \\
\hline & & \multicolumn{2}{|c|}{$n_{\mathrm{S}} \rightarrow \pi_{\mathrm{N}_{2} \mathrm{CS}}^{*}$} & \multicolumn{2}{|c|}{$\pi_{\mathrm{S}} \rightarrow \pi_{\mathrm{N}_{2} \mathrm{CS}}^{*}$} & \multicolumn{2}{|c|}{$\pi_{\mathrm{N}} \rightarrow \pi_{\mathrm{N}_{2}}^{*} \mathrm{Cs}$} & \multicolumn{2}{|l|}{ Others } \\
\hline & & obs $^{b}$ & calc $^{c}$ & obs $^{b}$ & calc $^{c}$ & obs $^{b}$ & calc $^{c}$ & obs $^{b}$ & calc $^{c}$ \\
\hline TMTU & isooctane & $\begin{array}{l}330 \\
(211)\end{array}$ & $\begin{array}{l}464 \\
(0.003)\end{array}$ & $\begin{array}{l}261 \\
(15810)\end{array}$ & $\begin{array}{l}294 \\
(0.165)\end{array}$ & $\begin{array}{l}240 \mathrm{sh} \\
(9000)\end{array}$ & $\begin{array}{l}239 \\
(0.115)\end{array}$ & $\begin{array}{l}219 \\
(5200)\end{array}$ & $\begin{array}{l}n_{\mathrm{S}} \rightarrow \sigma_{\mathrm{S}}^{*} / \pi_{\mathrm{S}}^{*} \\
211(0.0009) \\
204(0.0015)\end{array}$ \\
\hline \multicolumn{2}{|c|}{ TMTU $\cdot \mathrm{CH}_{3} \mathrm{I}$ ethanol } & - & - & $\begin{array}{l}220 \\
(15600)\end{array}$ & $\begin{array}{l}251 \\
(0.12)\end{array}$ & $\begin{array}{l}252 \\
(13300)\end{array}$ & $\begin{array}{l}260 \\
(0.09)\end{array}$ & $\begin{array}{l}211 \mathrm{sh} \\
(10000)\end{array}$ & $\begin{array}{l}\pi_{\mathrm{S}} \rightarrow \sigma_{\mathrm{S}}^{*} / \pi_{\mathrm{S}}^{*} \\
214(0.0015) \\
201(0.0061)\end{array}$ \\
\hline $\operatorname{TMTU} \cdot \mathrm{I}_{2}{ }^{e}$ & $\begin{array}{l}\text { perfluormethyl- } \\
\text { cyclohexane }\end{array}$ & - & - & - & $\begin{array}{l}332 \\
(0.094)\end{array}$ & 252 & $\begin{array}{l}243 \\
(0.055)\end{array}$ & $\begin{array}{l}235 \\
210 \mathrm{br}\end{array}$ & $\begin{array}{l}\pi_{\mathrm{S}} \rightarrow \sigma_{\mathrm{S}}^{*} / \pi_{\mathrm{S}}^{*} \\
280(0.005) \\
237(0.048)\end{array}$ \\
\hline $\mathrm{TMTU} \cdot \mathbf{H}^{+d}$ & conc. $\mathrm{H}_{2} \mathrm{SO}_{4}$ & - & - & $\begin{array}{l}230 \\
(8710)\end{array}$ & $\begin{array}{l}247 \\
(0.115)\end{array}$ & $\begin{array}{l}246 \\
(9120)\end{array}$ & $\begin{array}{l}269 \\
(0.147)\end{array}$ & - & - \\
\hline
\end{tabular}

${ }^{a}$ Approximate description based upon the CI-coefficients. ${ }^{b} \lambda_{\max }(\mathrm{nm})$, and, in parenthesis, $\varepsilon_{\max }\left(1 \mathrm{~mol}^{-1} \mathrm{~cm}^{-1}\right)$. c Transition wave length $(\mathrm{nm})$ and, in parenthesis, the oscillator strength. ${ }^{d}$ From Ref. $31 .{ }^{e}$ Charge transfer bands omitted. The calculated values are for tetramethylthiourea $S$-oxide. The observed bands are not well separated from TMTU and only approximate values are given in the table.

Table 4. Vertical ionization energies and CNDO/S orbital assignments of tetramethylthiourea compared with the shifts in the PES $^{a}$ of tetramethylselenourea.

\begin{tabular}{|c|c|c|c|c|}
\hline \multicolumn{3}{|c|}{ Tetramethylthiourea } & \multicolumn{2}{|c|}{ Tetramethylselenourea } \\
\hline Exp. $(e V)$ & Calc. $(\mathrm{eV})$ & Electron density ( $\%$ ) & Exp. $(\mathrm{eV})$ & Shift $(\mathrm{eV})$ \\
\hline 7.80 & 8.76 & $n_{\mathrm{S}}(92)$ & 7.35 & -0.45 \\
\hline 8.15 & 9.24 & $\pi_{\mathrm{s}}(77)$ & 7.70 & -0.45 \\
\hline 8.60 & 10.98 & $\pi_{N}(61)$ & 8.60 & 0 \\
\hline 11.25 & 13.43 & $\sigma_{\mathrm{CS}}(\mathrm{C}=22, \mathrm{~S}=48)$ & 11.05 & -0.20 \\
\hline 12.10 & 13.58 & $\pi_{\mathrm{N}_{2} \mathrm{CS}}(\mathrm{N}=30, \mathrm{C}=24, \mathrm{~S}=7)$ & 11.95 & -0.15 \\
\hline
\end{tabular}

${ }^{a}$ Photoelectron spectra.

$1137 \mathrm{~cm}^{-1}$. This can have two possible explanations. (1) One or both bands at $1137 \mathrm{~cm}^{-1}$ are actually displaced by $c a .15 \mathrm{~cm}^{-1}$ towards higher frequencies. This is contradicted by the results of the NCA which predict a small shift in the opposite direction. (2) The band in TMTU near $1150 \mathrm{~cm}^{-1}$ has been incorrectly assigned $^{2}$ and is instead the fundamental $v_{42} b$. This attribution is supported by the results obtained for tetramethylselenourea. ${ }^{3}$ In the IR spectrum of this compound (which is very similar to the spectrum of TMTU) the band near $1150 \mathrm{~cm}^{-1}$ of species $b$ is stronger than in TMTU and therefore supports the latter assignment.
From the results in Table 1 we can relate the IR shifts to perturbation of the skeletal modes in TMTU as was made for tetramethylurea. ${ }^{4}$ However, a more precise description can be given by discussing the GVFF changes of Table 2 in relation to the $\mathrm{CNDO} / \mathrm{S}$ electronic densities of Fig. 1.

The ground state electronic distribution of TMTU (top of Fig. 1) indicates a net charge of the $\left(\mathrm{CH}_{3}\right)_{2} \mathrm{~N}$ groups $(+0.08)$ and the thiocarbonyl carbon $(+0.40)$ while the sulfur atom has acquired a net negative charge of -0.57 . The predicted charge-densities are probably too high ( $c f$. the charge-density of -0.18 found for sulfur in TMTU by X-ray emission 
$\sigma$

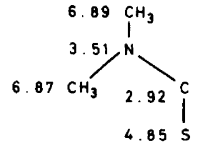

$\sigma$

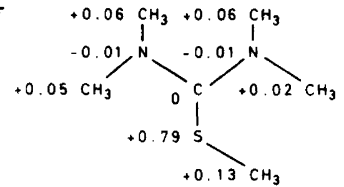

$\sigma$

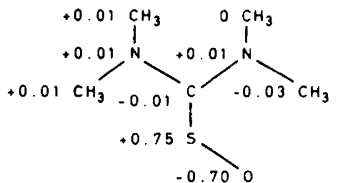

$\sigma$

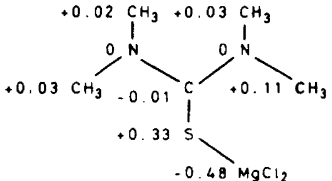

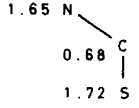

$\pi$

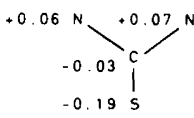

$\pi$

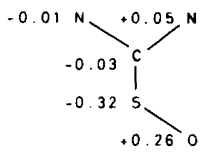

$\pi$

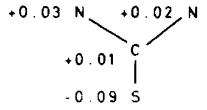

Fig. 1. The CNDO/S $\sigma$ - and $\pi$-electron density for TMTU and the changes on conversion to methiodide, $S$-oxide and metal halide complex. (Lower and higher densities relative to TMTU are indicated by the signs + and - , resp. The $\pi$-densities are taken at right angles to the $\mathrm{N}-\mathrm{CS}-\mathrm{N}$ plane).

spectroscopy ${ }^{27}$ ) while the signs and relative magnitudes are probably correct. The opposite $\sigma$ and $\pi$ orbital donor/acceptor properties of the $\mathrm{N}-\mathrm{CS}-\mathrm{N}$ group are general features of CNDO calculations. ${ }^{28}$ Conversion of TMTU to the charge-transfer complex TMTU $\cdot \mathrm{I}_{2}$ (exemplified by the $S$-oxide in Fig. 1) leads to an increased positive charge of sulfur $(+0.43)$ while the rest of the molecule is almost unaffected apart from the atoms closest to oxygen. In accordance with this the largest change in the GVFF (Table 2) is a decrease of $K_{D}$ upon chargetransfer of $0.48 \mathrm{mdyn} / \AA$. The negligible decrease in $K_{\mathrm{R}}, F_{\mathrm{R}}$, and $H_{\tau}$ suggest that the electron density of the $\mathrm{CN}$ bonds might decrease slightly. By varying the GVFF of TMTU $\cdot I_{2}$ it appears that only the sum of the force constants $H_{\gamma_{1}}, H_{\gamma^{\prime}}$, and $H_{\gamma_{3}}$ is significant. In accordance with $\mathrm{CNDO} / \mathrm{S}$ predictions this sum is almost unchanged from TMTU to TMTU $\cdot I_{2}$. The increase in the force constants $K_{\mathrm{P}_{1}}, H_{\delta_{1}}$, and $H_{\delta_{2}}$ might be connected with the increased resistance to stretching and bending caused by steric hindrance of coordinated iodine.

The force field of a metal halide complex of TMTU follows closely the pattern of TMTU $\cdot I_{2}$ (considering only the sum of $H_{\gamma_{1}}-H_{\gamma_{3}}$ ) except that the force constants $K_{\mathrm{R}}$ and $H_{\tau}$ have increased relative to TMTU. This trend agrees with the $\mathrm{CNDO} / \mathrm{S} \pi$-electron changes indicating an increased charge transfer from $\mathrm{N}$ to $\mathrm{S}$, i.e. an increased weight of ${ }^{+} \mathrm{N}=\mathrm{C}-\mathrm{S}^{-}$in classical terms. The same, but more pronounced trend occurs in the case of TMTU $\cdot \mathrm{CH}_{3} \mathrm{I}$. In agreement with a calculated enhanced ${ }^{+} \mathrm{N}=\mathrm{C}-\mathrm{S}^{-}$polarisation, $K_{\mathrm{R}}$ shows a substantial increase relative to TMTU $(+0.17)$ and the resistance towards NCN bending $\left(H_{\delta_{1}}\right)$ also rises sharply $(+0.91)$. The sum of the force constants $H_{\gamma_{1}}, H_{\gamma_{2}}$, and $H_{\gamma_{3}}$ is also less than in TMTU in accordance with the decreased electron density at nitrogen.

${ }^{13} \mathrm{C}$ NMR data have been obtained for TMTU and TMTU $\cdot I_{2}$. The chemical shift observed for the CS group at $180.3 \mathrm{ppm}$ in the iodine complex is shifted $13.8 \mathrm{ppm}$ upfield relative to TMTU (194.1 $\mathrm{ppm}$ ). This is consistent with the CNDO/S prediction (Fig. 1) of an increased thiocarbonyl carbon shielding $(-0.04)$ in the charge-transfer complex. However, since the mean excitation energy also exerts a strong influence on the chemical shift ${ }^{29}$ this result does not necessarily support the results of the $\mathrm{CNDO} / \mathrm{S}$ calculations.

The UV spectrum of TMTU has been the subject of empirical ${ }^{30,31}$ and theoretical (Hückel) ${ }^{32.33}$ investigations as has the charge-transfer spectra of the iodine complex. ${ }^{6-9}$ Since the thioureide group is non-planar the spectra are in many ways anomalous ${ }^{31}$ and may therefore function as a sensitive test for the predictability of the $\mathrm{CNDO} / \mathrm{S}-\mathrm{CI}$ calculations. The observed and calculated transitions are given in Table 3. The UV-spectrum of the iodine complex was recorded in perfluoromethylcyclohexane in order to avoid the contact charge-transfer spectrum of iodine. ${ }^{34}$ It is seen from the table that the calculated values for the $\pi_{\mathrm{S}} \rightarrow \pi_{\mathrm{N}_{2}}^{*} \mathrm{Cs}$ (and especially the $\left.n_{\mathrm{S}} \rightarrow \pi_{\mathrm{N}_{2} \mathrm{SS}}^{*}\right)$ transitions are too high. However, the CNDO/S - CI values reproduce the signs but not the magnitudes of the shifts of the $\pi_{\mathrm{S}} \rightarrow \pi_{\mathrm{N}_{2} \mathrm{CS}}^{*}$ and $\pi_{\mathrm{N}} \rightarrow \pi_{\mathrm{N}_{2} \mathrm{CS}}^{*}$ transitions from TMTU to the addition compounds. Tentatively, a few other bands in the short wave length region have been assigned to $n_{\mathrm{S}} / \pi_{\mathrm{S}} \rightarrow \sigma_{\mathrm{S}}^{*} / \pi_{\mathrm{S}}^{*}$ transitions in accordance with the calculated results.

The first four bands at ca. 7.80, 8.15, 8.60, and $11.25 \mathrm{eV}$ in the photoelectron spectrum of TMTU were assigned by Guimon et al. ${ }^{35}$ to ionisations in 
the order $n, \pi, \pi, \sigma$ by comparison with the calculated $(\mathrm{CNDO} / \mathrm{S})$ and experimental spectra of related thioureas. In a comparative study of amides, thioamides, ureas, and thioureas, Mines and Thompson ${ }^{36}$ considered instead the order of the first three bands to be $\pi, n, \pi$. The results of our CNDO/S calculations (Table 4) support the former assignment. It is seen that the third band $(8.60 \mathrm{eV})$ is calculated to rise from ionisation of an electron from an orbital localized on the nitrogen atoms while the four other bands originate in orbitals partly located on sulfur. Comparison with the photoelectron spectrum of tetramethylselenourea (Table 4) shows that the ionisation potential of the third band is unchanged while those of the other four bands are lowered. Since seleno compounds have spectra $^{37}$ similar to those of sulfur compounds except for bands due to ionisation from orbitals with $\mathrm{S}(\mathrm{Se})$ character, the orbital assignments of the $\mathrm{CNDO} / \mathrm{S}$ method are supported by these results.

Acknowledgements. We wish to thank Dr. L. Henriksen for his assistance in recording and interpreting the photoelectron spectra and Dr. $\mathrm{H}$. Eggert for assistance with the ${ }^{13} \mathrm{C}$ NMR spectra and stimulating discussions. This research was supported by grants from the Danish Natural Science Research Council and the Norwegian Research Council for Science and the Humanities.

\section{REFERENCES}

1. Jensen, K. A. and Nielsen, P. H. Acta Chem. Scand. 20 (1966) 597.

2. Anthoni, U., Nielsen, P. H., Borch, G., Gustavsen, J. and Klæboe, P. Spectrochim. Acta A 33 (1977) 403.

3. Anthoni, U., Nielsen, P. H., Borch, G. and Klæboe, P. Spectrochim. Acta. In press.

4. Muller, J.-P., Maes, G. and Zeegers-Huyskens, T. J. Chem. Phys. 71 (1974) 893.

5. Dorval, C. and Zeegers-Huyskens, T. Ann. Chim. Paris 10 (1975) 5.

6. Lang, R. P. J. Phys. Chem. 72 (1968) 2129.

7. Grand, A. F. and Tamres, M. Inorg. Chem. 8 (1969) 2495.

8. Niedzielski, R. J., Drago, R. S. and Middaugh, R. L. J. Am. Chem. Soc. 86 (1964) 1694.

9. Bhaskar, K. R., Gosavi, R. K. and Rao, C. N. R. Trans. Faraday Soc. 62 (1966) 29.

10. Gosavi, R. K., Agarwala, U. and Rao, C. N. R. J. Am. Chem. Soc. 89 (1967) 235.

11. Klæboe, P. J. Am. Chem. Soc. 89 (1967) 3667.

12. Schafer, M. and Curran, C. Inorg. Chem. 5 (1966) 265.

Acta Chem. Scand. A 32 (1978) No. 3
13. Gosavi, R. K. and Rao, C. N. R. J. Inorg. Nucl. Chem. 29 (1967) 1937.

14. Marcotrigiano, G. and Battistuzzi, R. J. Nucl. Chem. 36 (1974) 3719.

15. Devore, E. C. and Holt, S. L. J. Inorg. Nucl. Chem. 34 (1972) 2303.

16. Wynne, K. J., Pearson, P. S., Newton, M. G. and Golen, J. Inorg. Chem. 11 (1972) 1192.

17. Wynne, K. J. and Pearson, P. S. Chem. Commun. (1971) 293.

18. Wynne, K. J. and Pearson, P. S. Inorg. Chem. 10 (1971) 2735.

19. Ahlsen, E. L. and Strømme, K. O. Acta Chem. Scand. A 28 (1974) 175.

20. Hung-Yin Lin, G. and Hope, H. Acta Crystallogr. B 28 (1972) 643.

21. Husebye, S. and George, J. W. Inorg. Chem. 8 (1969) 313.

22. Spofford, W. A., Griffith, E. A. H. and Amma, E. L. Chem. Commun. (1970) 533.

23. Stam, C. H. Acta Crystallogr. 15 (1962) 317.

24. Kennard, O. and Walker, J. J. Chem. Soc. (1963) 5513.

25. Bene, J. D. and Jaffé, H. H. J. Chem. Phys. 48 (1968) 1807.

26. Arbelot, M., Guimon, C., Gonbeau, D. and Pfister-Guillouzo, G. J. Mol. Struct. 20 (1974) 487 , and earlier papers.

27. Takahashi, Y., Yabe, K. and Sato, T. Bull. Chem. Soc. Jpn. 42 (1969) 2707.

28. Clementi, E. Chem. Rev. 68 (1968) 341.

29. Martin, G. J., Martin, M. L. and Odiot, S. Org. Magn. Reson. 7 (1975) 2.

30. Gosavi, R. K. and Rao, C. N. R. Can. J. Chem. 45 (1967) 1897.

31. Fabian, J., Viola, H. and Mayer, R. Tetrahedron 23 (1967) 4323.

32. Figuera, J. M. and Menéndez, V. An. Quim. 67 (1971) 1169.

33. Chatterjee, K. K. Indian J. Chem. 11 (1973) 678.

34. Julien, L. M. and Person, W. B. J. Phys. Chem. 72 (1968) 3059.

35. Guimon, C., Pfister-Guillouzo, G., Arbelot, M. and Chanon, M. Tetrahedron 30 (1974) 3831; Guimon, C., Gonbeau, D., Pfister-Guillouzo, G., Åsbrink, L. and Sandström, J. J. Electron Spectrosc. Relat. Phenom. 4 (1974) 49.

36. Mines, G. W. and Thompson, H. W. Spectrochim. Acta 31 A (1975) 137.

37. Betteridge, G., Henriksen, L., Sandström, J., Wennerbeck, I. and Williams, M. A. Acta Chem. Scand. A 31 (1977) 14.

Received October 26, 1977. 